\title{
ВОЗМОЖНОСТИ ОЦЕНКИ МИКРОБИОТЫ ПОЛОСТИ МАТКИ С ИСПОЛЬЗОВАНИЕМ ПЦР В РЕАЛЬНОМ ВРЕМЕНИ
}

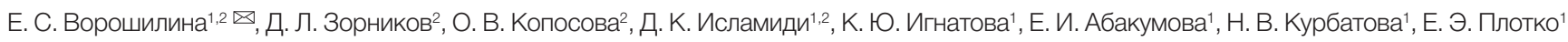

' Медицинский центр «Гармония», Екатеринбург, Россия

2 Уральский государственный медицинский университет, Екатеринбург, Россия

Наличие хронического эндометрита (ХЭ) у женщин репродуктивного возраста ассоциируют с бесплодием и невынашиванием беременности. Целью работы было оценить состояние микробиоты полости матки методом полимеразной цепной реакции в режиме реального времени (ПЦР-РВ) у женщин репродуктивного возраста в зависимости от морфологической картины эндометрия. С помощью теста «Андрослор» исследовали микробиоту аспирата эндометрия, полученного от 23 пациенток с ХЭ, 30 пациенток с гиперплазией эндометрия и 19 здоровых женщин. Во всех исследуемых образцах обнаружили ДНК от 1-9 групп микроорганизмов в количествах, превышающих показатели, полученные для отрицательных контрольных образцов. Общая бактериальная масса выявляемых микроорганизмов (ОБМ) составила 103-10,4 (медиана 103,8) ГЭ/мл. В 86,1\% случаев выявили Lactobacillus spp. Условно-патогенные микроорганизмы идентисицировали в 36,1\% образцов, в том числе в 22,2\% — в сочетании с лактобациллами и в 13,9\% без лактобацилл. У пациенток с ХЭ достоверно реже в сравнении с группой здоровых женщин выявляли вариант микробиоты, характеризующийся наличием Lactobacillus spp. с удельным весом в ОБМ не менее 90\%. Таким образом, метод ПЦР-РВ может быть использован для оценки микробиоты полости матки и позволяет определить ее особенности при различной морфологической картине эндометрия.

Ключевые слова: микробиота эндометрия, ПЦР-PB, хронический эндометрит, Lactobacillus spp.

Благодарности: авторы благодарят В. Хаютина, директора медицинского центра «Гармония» (г. Екатеринбург), за возможность выполнения исследования на базе центра. Авторы признательны Центру высокоточного редактирования и генетических технологий для биомедицины (Москва) за помощь в методах исследования.

Вклад авторов: Е. С. Ворошилина - организация исследования, молекулярно-генетические исследования, анализ данных, статистический анализ, написание статьи; Д. Л. Зорников - анализ данных, статистический анализ, написание статьи; О. В. Копосова - анализ данных, молекулярногенетические исследования; Д. К. Исламиди - клинический анализ, отбор пациентов, взятие образцов, написание статьи; К. Ю. Игнатова патоморфологические исследования; Е. И. Абакумова - клинический анализ, отбор пациентов, взятие образцов; Н. В. Курбатова - клинический анализ, отбор пациентов, взятие образцов; Е. Э. Плотко - организация исследования, анализ данных, написание статьи.

Соблюдение этических стандартов: исследование одобрено этическим комитетом Уральского государственнго медицинского университета (протокол № 7 от 20 сентября 2019 г.). Все участницы исследования подписали добровольное информированное согласие на проведение исследования.

$凶$ Для корреспонденции: Екатерина Сергеевна Ворошилина ул. Фурманова, д. 30, г. Екатеринбург, 620142; voroshilina@gmail.com

Статья получена: 03.02.2020 Статья принята к печати: 17.02.2020 Опубликована онлайн: 29.02.2020

DOI: $10.24075 /$ vrgmu.2020.012

\section{THE USE OF REAL-TIME PCR FOR EVALUATION OF ENDOMETRIAL MICROBIOTA}

Voroshilina ES ${ }^{1,2} \otimes$, Zornikov DL ${ }^{2}$, Koposova OV ${ }^{2}$, Islamidi DK¹,2, Ignatova $\mathrm{KY}^{1}$, Abakumova El ${ }^{1}$, Kurbatova NV¹, Plotko EE ${ }^{1}$

1 "Garmonia" Medical Center, Yekaterinburg, Russia

${ }^{2}$ Ural State Medical University, Yekaterinburg, Russia

Chronic endometritis (CE) in women of the reproductive age is associated with infertility and recurrent pregnancy loss. The aim of this study was to evaluate the endometrial microbiota by means of real-time PCR in reproductive-age women depending on the morphological pattern of the endometrium. Using the Androflor real-time PCR kit, we analyzed endometrial aspirate collected from 23 patients with chronic endometritis, 30 patients with endometrial hyperplasia, and 19 healthy women. DNA of up to 9 groups of microorganisms was detected in all the analyzed samples in the amounts exceeding negative control. The total bacterial load (TBL) of the detected microorganisms was $10^{3}-10^{6,4}$ (median 10 $0^{3,8}$ ) GE/ml. Lactobacillus spp. were detected the most often (86.1\% of all samples). Opportunistic microorganisms (OM) were identified in $36.1 \%$ of all samples, including $22.2 \%$ of samples with lactobacilli and $13.9 \%$ - without lactobacilli. The variant of microbiota composition with Lactobacillus-dominance (more than $90 \%$. in the TBL) was detected significantly less often in women with chronic endometritis compared to healthy women. Real-time PCR could be used for assessment of endometrial microbiota and allows us to determine its characteristics depending on the morphological pattern.

Keywords: endometrial microbiota, real-time PCR, chronic endometritis, Lactobacillus spp.

Acknowledgement: the authors thank Khayutin V, director of "Garmonia" Medical Center (Yekaterinburg), for letting them use its facilities for this research study. We thank to the Center for Precision Genome Editing and Genetic Technologies for Biomedicine (Moscow) for the genetic research methods.

Author contribution: Voroshilina ES organized the study, reviewed the literature, performed real-time PCR and statistical analysis, contributed to manuscript preparation; Zornikov DL reviewed the literature, conducted statistical analysis, contributed to manuscript preparation; Koposova OV reviewed the literature, performed molecular genetic assays; Islamidi DK analyzed medical histories, recruited patients, performed endometrial aspiration and pipelle biopsies, contributed to manuscript preparation; Ignatova KY conducted histological examinations; Abakumova El reviewed medical histories, recruited patients, performed endometrial aspiration and pipelle biopsies; Kurbatova NV reviewed medical histories, recruited patients, performed endometrial aspiration and pipelle biopsies; Plotko EE organized the study, reviewed the literature, contributed to manuscript preparation.

Compliance with ethical standards: the study was approved by the Ethics Committee of Ural State Medical University (Protocol № 7 dated September 20, 2019). Informed consent was obtained from all study participants.

$\triangle$ Correspondence should be addressed: Ekaterina C. Voroshilina Furmanova, 30, Yekaterinburg, 620142; voroshilina@gmail.com

Received: 03.02.2020 Accepted: 17.02.2020 Published online: 29.02.2020

DOI: $10.24075 / \mathrm{brsmu} .2020 .012$ 
На протяжении долгого времени полость матки считали стерильным биотопом [1]. Однако в настоящее время применение молекулярно-генетических методов исследования позволяет выявлять ассоциации трудно культивируемых и некультивируемых микроорганизмов на поверхности эндометрия у женщин репродуктивного возраста [2-7]. Нет единой точки зрения о вкладе тех или иных групп условно-патогенных микроорганизмов (УПМ) в развитие воспалительной патологии эндометрия [8, 9], и это вызывает сомнения в целесообразности назначения антимикробной терапии при хроническом эндометрите (ХЭ). Важно отметить, что ХЭ выявляют примерно у $10 \%$ женщин репродуктивного возраста [10], а его наличие ассоциируют с бесплодием и невынашиванием беременности [1, 8, 11-14].

Интерпретация положительных результатов, полученных с помощью молекулярно-генетических методик, затруднена вследствие возможной контаминации исследуемых образцов. С одной стороны, источником контаминации может быть микробиота влагалища или шейки матки, так как в клинической практике используют трансцервикальный способ взятия биоматериала [5, 6]. С другой стороны, положительные результаты могут быть обусловлены наличием малых концентраций бактериальной ДНК в самих наборах реагентов для проведения молекулярно-генетических исследований (так называемый kitome), избавиться от которой не представляется возможным по ряду технических причин [15]. Последнее не является проблемой при исследовании биоматериалов с высоким содержанием микроорганизмов (например, фекалии или вагинальное отделяемое), так как концентрации исследуемой ДНК гораздо выше китомной. Однако при исследовании эндометрия, концентрация микроорганизмов в котором редко превышает $10^{4}$ клеток на образец, данный момент становится критичным [16].

Кроме того, стоит отметить, что большинство исследований микробиоты эндометрия выполнено с использованием метода секвенирования нового поколения (NGS-секвенирования) [3-6] - дорогостоящего подхода, плохо адаптированного для практического здравоохранения. Наиболее подходящий для рутинных исследований молекулярно-генетический метод полимеразная цепная реакция в режиме реального времени (ПЦР-РВ). Однако на сегодняшний день отмечены лишь единичные отчеты об использовании данной методики при исследовании микробиоты эндометрия [7, 17].

Цель настоящего исследования — оценить состояние микробиоты полости матки методом ПЦР-РВ у женщин репродуктивного возраста в зависимости от морфологической картины эндометрия.

\section{ПАЦИЕНТЫ И МЕТОДЫ}

\section{Группа обследованных}

В исследование были включены 72 женщины репродуктивного возраста (21-45 лет, средний возраст составил $33 \pm 5,2$ года), обратившиеся в медицинский центр «Гармония» (г. Екатеринбург) в период с сентября по декабрь 2019 г. Все женщины обратились с целью решения репродуктивных проблем или в рамках предгравидарной подготовки.

Критерии включения: репродуктивный возраст 18-45 лет, интервальный период (вне беременности), регулярный менструальный цикл; отягощенный акушерскогинекологический анамнез: бесплодие, искусственные и самопроизвольные аборты, неразвивающаяся беременность, хронический эндометрит.

Критерии исключения: гормональная и внутриматочная контрацепция на момент обследования и в течение предшествующих 6 месяцев; онкологические заболевания любой локализации; ВИЧ-инфекция; наличие острых воспалительных заболеваний нижних отделов гениталий и органов малого таза на момент обследования; антибактериальная терапия в течение четырех недель до обследования.

\section{Техника получения образцов эндометрия}

Исследование проводили на 7-10-й день менструального цикла. Аспират эндометрия для исследования микробиоты отбирали с помощью устройства для получения эндометральной цитологии Endobrash Standard for Endometrial Cytology (Laboratoire C.C.D.; Франция). Данное устройство снабжено специальным защитным проводником, который предохраняет расположенную внутри него щетку от контакта со слизистой цервикального канала. Щетка раскрывается только после введения в полость матки, а перед извлечением задвигается внутрь проводника. Предварительно шейку матки выводили в зеркалах, очищали тампоном, смоченным 0,05\%-м раствором хлоргексидина, затем вводили устройство, не касаясь стенок влагалища, в полость матки. После извлечения устройства из полости матки поверхность проводника дополнительно протирали стерильным тампоном, смоченным 95\%-м этиловым спиртом для удаления отделяемого цервикального канала и предотвращения контаминации пробы его микрофлорой. Затем выдвигали щетку с образцом эндометрия и переносили в жидкость PreservCyt Solution для консервирования клеточных образцов при диагностике in vitro (Hologic, Inc.; США).

После аспирации эндометрия для исследования микробиоты у всех пациенток отбирали образцы эндометрия для гистологического исследования методом пайпель-биопсии, которые помещали во флаконы с 10\%-м забуференным раствором формалина.

\section{Выделение ДНК}

Для выделения ДНК использовали набор ПРОБА-НКПЛЮС («ДНК-Технология»; Россия). Образцы эндометрия подвергали предварительной депротеинизации по следующей методике. Пробирки с аспиратом эндометрия центрифугировали 10 мин при 13000 об./мин на центрифуге MiniSpin (Eppendorf; Германия), удаляли надосадочную жидкость, осадок ресуспендировали в 100 мкл лизирующего раствора из набора ПРОБА-НК-ПЛЮС. Переносили 50 мкл гомогенизата в чистую пробирку, содержащую смесь из 25 мкл лизирующего раствора из набора ПРОБА-НК-ПЛЮС, 5 мкл протеиназы К (20 мг/мл) (VWR Life Science; США) и 120 мкл стерильного физиологического раствора. После перемешивания образцы инкубировали при $60{ }^{\circ} \mathrm{C}$ в течение 30 мин, далее при $95{ }^{\circ} \mathrm{C}$ в течение 10 мин. По окончании инкубации пробирки центрифугировали 60 с при 13000 об.\ мин. Надосадочную жидкость в объеме 100 мкл использовали для выделения ДНК согласно инструкции производителя.

\section{Оценка микробиоты эндометрия}

Выявление ДНК облигатно-патогенных возбудителей инфекций, передающихся половым путем (ИППП), и 
условно-патогенных микроорганизмов (УПМ) методом полимеразной цепной реакции в реальном времени (ПЦРPВ) в аспирате эндометрия проводили с помощью набора «Андрофлор» («ДНК-Технология»; Россия), включающего максимально широкий перечень микроорганизмов, важных в поисковой работе для установления роли инфекционного фактора в развитии воспалительной патологии эндометрия. Тест-система позволяет провести количественную оценку 24 групп микроорганизмов: Lactobacillus spp., Staphylococcus spp., Streptococcus spp., Corynebacterium spp., Gardnerella vaginalis (G. vaginalis), Megasphaera spp., Veillonella spp., Dialister spp., Sneathia spp., Leptotrichia spp., Fusobacterium spp., Ureaplasma urealyticum (U. urealyticum), Ureaplasma parvum (U. parvum), Mycoplasma hominis (M. hominis), Atopobium cluster, Bacteroides spp., Porphyromonas spp., Prevotella spp., Anaerococcus spp., Peptostreptococcus spp., Parvimonas spp., Eubacterium spp., Haemophilus spp., Pseudomonas aeruginosa, Ralstonia spp., Burkholderia spp., Enterobacteriaceae spp./Enterococcus spp., Trichomonas vaginalis (T. vaginalis), Neisseria gonorrhoeae (N. gonorrhoeae), Chlamydia trachomatis (C. trachomatis), Mycoplasma genitalium (M. genitalium), Candida spp. ПЦР-РВ проводили на детектирующем амплификаторе ДТпрайм ЧМ1 («ДНК-Технология»; Россия).

Количество каждого микроорганизма или группь микроорганизмов рассчитывали по пороговому циклу амплификации, затем определяли его долю относительно общей бактериальной массы (ОБМ). В качестве отрицательных контрольных образцов (ОКО) использовали стерильную деионизированную воду. В OKO положительные сигналы по некоторым группам микроорганизмов в ПЦР-РВ фиксировали не ранее 35-го цикла ампилификации (что соответствовало микробной нагрузке менее $10^{3}$ геном-эквивалентов на образец, или ГЭ/образец). На основании этого значимым считали количество микроорганизмов не менее $10^{3}$ ГЭ/образец, что соответствовало положительному сигналу в ПЦР-РВ до 35-го цикла. Меньшие показатели рассматривали как отрицательные с учетом высокой чувствительности метода и невозможности дифференцировать положительные сигналы, получаемые в ОКО и образцах с крайне низким содержанием бактериальной ДНК.

Исключение составляли U. urealyticum, U. parvum, M. hominis, по которым положительный сигнал в ОКО отсутствовал. При получении сигнала на любом цикле амплификации результат ПЦР-РВ по этим группам микроорганизмов расценивали как положительный.

\section{Патоморфологическое исследование}

Морфологическому исследованию подвергали ткань эндометрия, полученную при пайпель-биопсии. Материал фиксировали в забуференном 10\%-м нейтральном формалине и обрабатывали по общепринятой методике. Парафиновые срезы стандартной толщины (5,0 мкм) окрашивали гематоксилином и эозином. Микроскопическое исследование проводили с применением светового бинокулярного микроскопа Eclipse E200 (Nikon; Япония) (объективы 10, 40; окуляры 10).

\section{Статистические методы}

Средний возраст пациенток выражали средним арифметическим и стандартным отклонением. В качестве средних величин ОБМ и количеств отдельных групп микроорганизмов использовали медианы. Для отображения дисперсии признака внутри групп указывали процентили 0,05 и 0,95. Все перечисленные показатели рассчитывали в программе Microsoft Office Excel 2007 (Microsoft Corp.; CША).

Для оценки достоверности различий между средними показателями ОБМ и количеством отдельных групп микроорганизмов рассчитывали критерии КраскелаУоллеса (при сравнении показателей между тремя исследуемыми группами) и Манна-Уитни (при сравнении показателей между двумя исследуемыми группами) в программе IBM SPSS Statistics 20 (IBM Corp.; CША). Для оценки достоверности различий частотных показателей в исследуемых группах рассчитывали двусторонний критерий Фишера с помощью свободно распространяемого продукта WinPepi (JH Abramson; Израиль). Во всех случаях различия интерпретировали как достоверные при $p<0,05$.

\section{РЕЗУЛЬТАТЫ ИССЛЕДОВАНИЯ}

\section{Результаты патоморфологического исследования эндометрия}

В зависимости от морфологической картины эндометрия все обследованные пациентки были разделены на три группы [18].

В группу 1 (хронический эндометрит, ХЭ) вошли 23 пациентки с хроническим эндометритом. Диагноз верифицирован на основании выявления признаков продуктивного воспаления с формированием лимфоидных фолликулов и фриброза стромы эндометрия, склеротических изменений стенок спиральных артерий.

В группу 2 (гиперплазия эндометрия, ГПЭ) вошли 30 пациенток с простой гиперплазией эндометрия без атипии. Диагноз основан на гистологическом выявлении признаков пролиферации в железистых криптах и цитогенной строме эндометрия, спиральных артериях с наличием/отсутствием клеточного и ядерного полиморфизма.

В группу 3 (норма) включили 19 пациенток, у которых при гистологическом исследовании не было выявлено структурных изменений эндометрия и он соответствовал дню менструального цикла.

\section{Результаты молекулярно-биологического исследования}

Во всех 72 образцах аспирата эндометрия была выявлена бактериальная ДНК: ОБМ определяли в диапазоне $10^{3}-10^{6,4}$ (медиана 103,8) ГЭ/образец. Не было выявлено существенных различий по данному показателю между группами пациенток с патологией эндометрия и без таковой. Таким образом, детектируемый методом ПЦР-РВ уровень ОБМ в полости матки отличался в 100-10 000 раз от показателей, типичных для влагалища женщин репродуктивного возраста [19].

Чаще всего в исследованных образцах эндометрия определяли Lactobacillus spp. - в 62 (86,1\%) из 72 образцов. G. vaginalis выявили в 19 (26,8\%) пробах, U. parvum в $9(12,7 \%)$ пробах и группу Enterobacteriaceae spp. / Enterococcus spp. - в 8 (11,3\%) образцах. Прочие группы микроорганизмов определяли в единичных пробах (табл. 1).

Отдельные группы микроорганизмов выявляли с разной частотой у женщин с различной гистологической картиной. Несмотря на отсутствие статистически значимых различий (что возможно обусловлено малой численностью групп) были выявлены некоторые интересные тенденции. 
Таблица 1. Частота выявления отдельных групп микроорганизмов методом ПЦР-РВ в образцах эндометрия с различной гистологической картиной

\begin{tabular}{|l|c|c|c|c|}
\hline \multicolumn{1}{|c|}{ Группы микроорганизмов } & \multicolumn{4}{|c|}{ Частота выявления отдельных групп микроорганимов в обследованных группах (n/ \%) } \\
\hline & $\begin{array}{c}\text { Группа } 1-\text { ХЭ } \\
N=23\end{array}$ & $\begin{array}{c}\text { Группа } 2-\text { ГпЭ } \\
N=30\end{array}$ & $\begin{array}{c}\text { Группа } 3-\text { норма } \\
N=19\end{array}$ & $\begin{array}{c}\text { Всего } \\
N=72\end{array}$ \\
\hline Lactobacillus spp. & $19 / 82,6$ & $25 / 83,3$ & $18 / 94,7$ & $62 / 86,1$ \\
\hline Staphylococcus spp. & 0 & 0 & 0 & 0 \\
\hline Streptococcus spp. & $1 / 4,3$ & 0 & 0 & $1 / 1,4$ \\
\hline Corynebacterium spp. & 0 & $3 / 10,0$ & 0 & $3 / 4,2$ \\
\hline Gardnerella vaginalis & $7 / 30,4$ & $9 / 30,0$ & $3 / 15,8$ & $19 / 26,4$ \\
\hline Megasphaera spp. / Veillonella spp. / Dialister spp. & $1 / 4,3$ & $2 / 6,7$ & 0 & $3 / 4,2$ \\
\hline Sneathia spp. / Leptotrichia spp. / Fusobacterium spp. & $1 / 4,3$ & 0 & 0 & $1 / 1,4$ \\
\hline Atopobium cluster & $1 / 4,3$ & $3 / 10,0$ & 0 & $4 / 5,6$ \\
\hline Bacteroides spp. / Porphyromonas spp. / Prevotella spp. & $2 / 8,7$ & $3 / 10,0$ & $2 / 10,5$ & $7 / 9,7$ \\
\hline Anaerococcus spp. & 0 & $1 / 3,3$ & 0 & $1 / 1,4$ \\
\hline Peptostreptococcus spp. / Parvimonas spp. & $2 / 8,7$ & 0 & $2 / 10,5$ & $4 / 5,6$ \\
\hline Eubacterium spp. & $2 / 8,7$ & $3 / 10,0$ & $1 / 5,3$ & $6 / 8,3$ \\
\hline Haemophilus spp. & $1 / 4,3$ & 0 & 0 & $1 / 1,4$ \\
\hline Pseudomonas aeruginosa / Ralstonia spp. / Burkholderia spp. & 0 & $1 / 3,3$ & 0 & $1 / 1,4$ \\
\hline Enterobacteriaceae spp. / Enterococcus spp. & $4 / 17,4$ & $3 / 10,0$ & $1 / 5,6$ & $8 / 11,3$ \\
\hline Ureaplasma urealyticum & 0 & $1 / 3,3$ & 0 & $1 / 1,4$ \\
\hline Ureaplasma parvum & $4 / 17,4$ & $4 / 13,3$ & $1 / 5,3$ & $9 / 12,5$ \\
\hline Mycoplasma hominis & $3 / 13,0 \%$ & $2 / 6,7$ & & $5 / 6,9$ \\
\hline
\end{tabular}

В образцах, гистологическая картина которых соответствовала норме, выявляли ограниченное число групп УПМ. В то время как у пациенток с ХЭ и ГПЭ выявляли все определяемые группы УПМ, за исключением Staphylococcus spp.

Некоторые УПМ чаще выявляли у женщин с ХЭ и ГПЭ. Так, ДНК G. vaginalis присутствовала в 30\% образцов у пациенток с патологией эндометрия, а у женщин группы нормы только в 16,7\% проб. ДНК U. parvum и M. hominis была определена в 17,4 и 13,0\% образцов, которые гистологически отвечали критериям ХЭ, в то время как у женщин группы нормы только в одном образце была выявлена U. parvum.

Облигатно патогенные возбудители ИППП отсутствовали в эндометрии обследованных пациенток.

В разных образцах эндометрия определяли 1-9 групп микроорганизмов (рис. 1). Микробиота эндометрия женщин группы нормы в 78,9\% случаев (15 из 19 проб) была представлена одной группой микроорганизмов, в то время как у пациенток с ХЭ одну группу микроорганизмов определяли в $9(39,1 \%)$ из 23 образцов ( $p=0,013)$. У пациенток с ХЭ чаще всего одновременно определяли две группы бактерий (в 11 (47,8\%) из 23 образцов). У пациенток с ГПЭ одну группу микроорганизмов определяли в 16 (53,3\%) из 30 случаев, в остальных пробах микробиота была представлена двумя и более группами микроорганизмов. В целом образцы эндометрия, гистологическая картина которых соответствует ГПЭ и ХЭ, отличало большее видовое разнообразие микробиоты.

Количественные показатели для каждой из определяемых групп микроорганизмов представлены в табл. 2. При сравнении трех групп, сформированных на основе гистологического заключения (ХЭ, ГПЭ, норма), статистически достоверных различий получено не было.

Учитывая значительное количество определяемых групп микроорганизмов, было принято решение определять

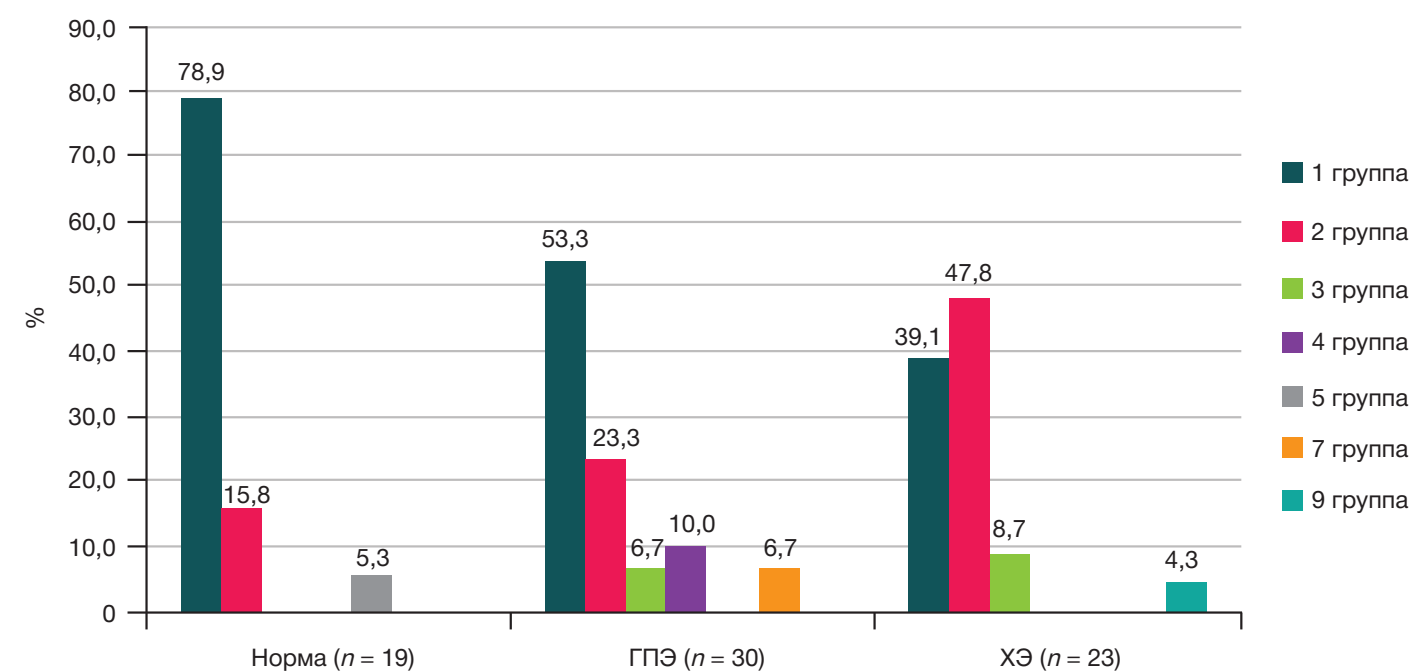

Рис. 1. Число одновременно определяемых групп микроорганизмов в образцах эндометрия у пациенток с различной гистологической картиной ( $p=0,013)$ 
Таблица 2. Качественный и количественный состав микробиоты эндометрия по данным ПЦР-РВ у обследованных групп женщин (N= 72)

\begin{tabular}{|c|c|c|c|c|}
\hline \multirow{2}{*}{ Группы определяемых микроорганизмов } & \multicolumn{4}{|c|}{$\begin{array}{c}\text { Медиана } \\
(0,05-0,95 \text { процентиль) }\end{array}$} \\
\hline & $\begin{array}{c}\text { Группа } 1 \\
\text { XЭ, } N=23\end{array}$ & $\begin{array}{c}\text { Группа } 2 \\
\Gamma П Э, N=30\end{array}$ & $\begin{array}{c}\text { Группа } 3 \\
\text { Норма, } N=19\end{array}$ & $\begin{array}{l}\text { Bсего } \\
N=72\end{array}$ \\
\hline ОБМ & $\begin{array}{c}10^{3,8} \\
\left(10^{3,2}-10^{4,7}\right)\end{array}$ & $\begin{array}{c}10^{3,8} \\
\left(10^{3,3}-10^{5,1}\right)\end{array}$ & $\begin{array}{c}10^{3,9} \\
\left(10^{3,3}-10^{5,1}\right)\end{array}$ & $\begin{array}{c}10^{3,8} \\
\left(10^{3,3}-10^{5,1}\right)\end{array}$ \\
\hline Lactobacillus spp. & $\begin{array}{c}10^{3,8} \\
\left(0-10^{4,6}\right)\end{array}$ & $\begin{array}{c}10^{3,7} \\
\left(0-10^{5,1}\right)\end{array}$ & $\begin{array}{c}10^{3,8} \\
\left(10^{2,6}-10^{5,1}\right)\end{array}$ & $\begin{array}{c}10^{3,8} \\
\left(0-10^{4,9}\right)\end{array}$ \\
\hline Staphylococcus spp. & $\begin{array}{l}0 \\
0\end{array}$ & $\begin{array}{l}0 \\
0\end{array}$ & $\begin{array}{l}0 \\
0\end{array}$ & $\begin{array}{l}0 \\
0\end{array}$ \\
\hline Streptococcus spp. & $\begin{array}{l}0 \\
0\end{array}$ & $\begin{array}{l}0 \\
0\end{array}$ & $\begin{array}{l}0 \\
0\end{array}$ & $\begin{array}{l}0 \\
0\end{array}$ \\
\hline Corynebacterium spp. & $\begin{array}{l}0 \\
0\end{array}$ & $\begin{array}{c}0 \\
\left(0-10^{3,1}\right)\end{array}$ & $\begin{array}{l}0 \\
0\end{array}$ & $\begin{array}{l}0 \\
0\end{array}$ \\
\hline Gardnerella vaginalis & $\begin{array}{c}0 \\
\left(0-10^{3,8}\right) \\
\end{array}$ & $\begin{array}{c}0 \\
\left(0-10^{3,7}\right) \\
\end{array}$ & $\begin{array}{c}0 \\
\left(0-10^{3,2}\right) \\
\end{array}$ & $\begin{array}{c}0 \\
\left(0-10^{3,8}\right)\end{array}$ \\
\hline Megasphaera spp. / Veillonella spp. / Dialister spp. & $\begin{array}{l}0 \\
0\end{array}$ & $\begin{array}{l}0 \\
0\end{array}$ & $\begin{array}{l}0 \\
0\end{array}$ & $\begin{array}{l}0 \\
0\end{array}$ \\
\hline Sneathia spp. / Leptotrichia spp. / Fusobacterium spp. & $\begin{array}{l}0 \\
0\end{array}$ & $\begin{array}{l}0 \\
0\end{array}$ & $\begin{array}{l}0 \\
0\end{array}$ & $\begin{array}{l}0 \\
0\end{array}$ \\
\hline Atopobium cluster & $\begin{array}{l}0 \\
0\end{array}$ & $\begin{array}{c}0 \\
\left(0-10^{3,2}\right)\end{array}$ & $\begin{array}{l}0 \\
0\end{array}$ & $\begin{array}{c}0 \\
\left(0-10^{1,5}\right)\end{array}$ \\
\hline Bacteroides spp. / Porphyromonas spp. / Prevotella spp. & $\begin{array}{l}0 \\
0\end{array}$ & $\begin{array}{c}0 \\
\left(0-10^{3,2}\right)\end{array}$ & $\begin{array}{c}0 \\
\left(0-10^{3,3}\right)\end{array}$ & $\begin{array}{c}0 \\
\left(0-10^{3,2}\right)\end{array}$ \\
\hline Anaerococcus spp. & $\begin{array}{l}0 \\
0\end{array}$ & $\begin{array}{l}0 \\
0\end{array}$ & $\begin{array}{l}0 \\
0\end{array}$ & $\begin{array}{l}0 \\
0\end{array}$ \\
\hline Peptostreptococcus spp. / Parvimonas spp. & $\begin{array}{c}0 \\
\left(0-10^{2,8}\right)\end{array}$ & $\begin{array}{l}0 \\
0\end{array}$ & $\begin{array}{c}0 \\
\left(0-10^{3,0}\right)\end{array}$ & $\begin{array}{c}0 \\
\left(0-10^{1,5}\right)\end{array}$ \\
\hline Eubacterium spp. & $\begin{array}{c}0 \\
\left(0-10^{2,7}\right)\end{array}$ & $\begin{array}{c}0 \\
\left(0-10^{3,0}\right)\end{array}$ & $\begin{array}{c}0 \\
\left(0-10^{0,5}\right)\end{array}$ & $\begin{array}{c}0 \\
\left(0-10^{3,0}\right)\end{array}$ \\
\hline Haemophilus spp. & $\begin{array}{l}0 \\
0\end{array}$ & $\begin{array}{l}0 \\
0\end{array}$ & $\begin{array}{l}0 \\
0\end{array}$ & $\begin{array}{l}0 \\
0\end{array}$ \\
\hline Pseudomonas aeruginosa/Ralstonia spp. / Burkholderia spp. & $\begin{array}{l}0 \\
0\end{array}$ & $\begin{array}{l}0 \\
0\end{array}$ & $\begin{array}{l}0 \\
0\end{array}$ & $\begin{array}{l}0 \\
0\end{array}$ \\
\hline Enterobacteriaceae spp. / Enterococcus spp. & $\begin{array}{c}0 \\
\left(0-10^{3,3}\right)\end{array}$ & $\begin{array}{c}0 \\
\left(0-10^{3,1}\right)\end{array}$ & $\begin{array}{c}0 \\
\left(0-10^{0,5}\right)\end{array}$ & $\begin{array}{c}0 \\
\left(0-10^{3,2}\right)\end{array}$ \\
\hline Ureaplasma urealyticum & $\begin{array}{l}0 \\
0\end{array}$ & $\begin{array}{l}0 \\
0\end{array}$ & $\begin{array}{l}0 \\
0\end{array}$ & $\begin{array}{l}0 \\
0\end{array}$ \\
\hline Ureaplasma parvum & $\begin{array}{c}0 \\
\left(0-10^{1,9}\right)\end{array}$ & $\begin{array}{c}0 \\
\left(0-10^{1,9}\right)\end{array}$ & $\begin{array}{c}0 \\
\left(0-10^{0,1}\right)\end{array}$ & $\begin{array}{c}0 \\
\left(0-10^{1,8}\right)\end{array}$ \\
\hline Mycoplasma hominis & $\begin{array}{c}0 \\
\left(0-10^{2,4}\right)\end{array}$ & $\begin{array}{c}0 \\
\left(0-10^{1,1}\right)\end{array}$ & $\begin{array}{l}0 \\
0\end{array}$ & $\begin{array}{c}0 \\
\left(0-10^{2,2}\right)\end{array}$ \\
\hline
\end{tabular}

суммарное количество УПМ в образце. Далее рассчитывали долю лактобацилл и суммарную долю УПМ относительно ОБМ. На основании этих показателей выделили три варианта микробиоты эндометрия.

1. С преобладанием Lactobacillus spp. Доля лактобацилл составляла не менее 90\% в ОБМ, а остальные группы микроорганизмов отсутствовали либо были представлень в незначительных количествах (менее 10\% относительно ОБМ).

2. Смешанный тип микробиоты. Доля лактобацилл составляла не более 90\% в ОБМ, соответственно, доля УПМ составляла не менее 10\% в ОБМ. В зависимости от преобладающей группы УПМ возможно выделение подвариантов данного типа микробиоты.

3. Микробиота представлена исключительно УПМ в отсутствие Lactobacillus spp. В зависимости от того, какая группа УПМ была выявлена, возможно выделение подвариантов данного типа микробиоты.

Критериям варианта 1 соответствовали 46 (63,9\%) из 72 образцов, варианта 2 - 16 (22,2\%) образцов, варианта
3 - 10 (13,9\%) образцов. Таким образом, у большинства обследованных женщин микробиота эндометрия была представлена исключительно лактобациллами или сочетанием лактобацилл с УПМ. Далее проанализировали частоту выявления предложенных вариантов микробиоты эндометрия в исследуемых группах.

У женщин группы нормы в 16 (84,2\%) из 19 образцов микробиота эндометрия соответствовала критериям варианта 1 - с преобладанием лактобацилл (рис. 2). Критериям варианта 2 соответствовали два (10,5\%) из 19 образцов. Вариант 3 (представленный исключительно УПМ) был определен только в одном (5,3\%) образце. Примечательно, что УПМ во всех трех образцах была представлена G. vaginalis.

У пациенток с ГПЭ варианты 2 и 3 определяли несколько чаще по сравнению с группой нормы, однако различия были статистически не достоверны. Критериям варианта 2 соответствовали пять (16,7\%) из 30 образцов, при этом УПМ во всех случаях была представлена G. vaginalis. Вариант 3 (представленный исключительно 


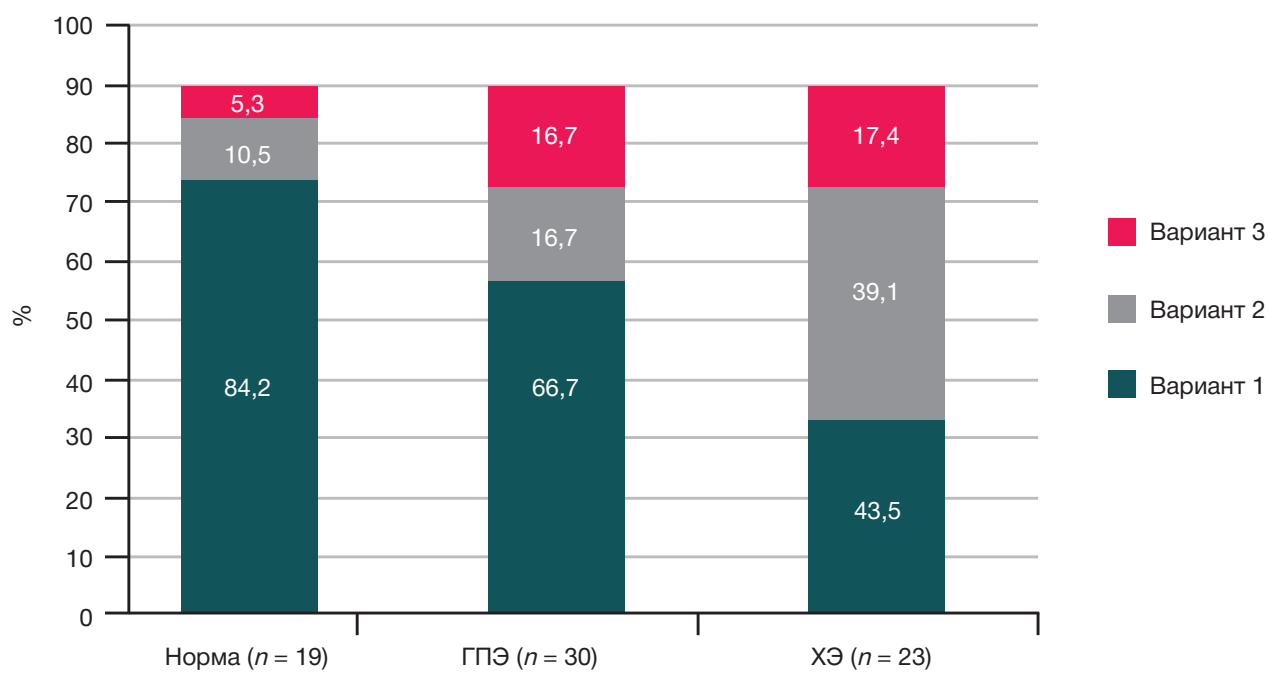

Рис. 2. Частота выявления отдельных вариантов микробиоты в аспирате эндометрия у женщин с различной гистологической картиной эндометрия $\left({ }^{*} p=0,011\right)$

УПМ) определили также в пяти (16,7\%) образцах, в четырех из них УПМ была представлена G. vaginalis, в одном группой Enterobacteriaceae spp. / Enterococcus spp.

Наибольшее разнообразие вариантов микробиоты определяли в образцах эндометрия пациенток с ХЭ. Критериям варианта 1 (с преобладанием лактобацилл) соответствовали только 10 (43,5\%) из 23 образцов ( 2 соответствовала микробиота девяти (39,1\%) проб, при этом в пяти пробах УПМ была представлена анаэробами (G.vaginalis и Bacteroides spp. / Porphyromonas spp. I Prevotella spp.). В четырех пробах УПМ была представлена факультативно анаэробными грамположительными и грамотрицательными бактериями. Критериям варианта 3 соответствовало четыре $(17,4 \%)$ из 23 проб. При этом УПМ была представлена исключительно G. vaginalis в двух случаях, Enterobacteriaceae spp. / Enterococcus spp. в одном случае; ассоциацией Peptostreptococcus spp. / Parvimonas spp. и Enterobacteriaceae spp. / Enterococcus spp. - в одном случае.

Таким образом, у пациенток с ХЭ чаще выявляли варианты микробиоты, в составе которых присутствовали представители УПМ.

\section{ОБСУЖДЕНИЕ РЕЗУЛЬТАТОВ}

В настоящем исследовании оценку микробиоты эндометрия мы производили методом ПЦР-РВ на доступном оборудовании с использованием стандартных реагентов. Полученные результаты по ключевым позициям согласуются с данными, полученными ранее другими исследователями с применением высокотехнологичных дорогостоящих методов [2-6], не применимых в клинической практике.

Во всех исследованных образцах аспирата эндометрия выявлена бактериальная ДНК, при этом количество ее составляло $10^{3}-10^{5}$ ГЭ/образец и различалось между образцами не более чем в 10-100 раз. Аналогичные данные были получены в других исследованиях при получении материала трансцервикальным путем [2, 5, 6]. Такой способ отбора материала потенциально чреват риском контаминацией $[5,6]$, что может объяснять присутствие бактериальной ДНК во всех исследуемых образцах. Ради чистоты эксперимента были исследованы образцы эндометрия, полученные из средней зоны полости матки, извлеченной путем трансабдоминальной гистеректомии у пациенток позднего репродуктивного возраста, страдавших патологией матки и эндометрия [20]. При таком подходе авторы выявили бактериальную ДНК (в количестве, превышающем показатели ОКО) в 60\% образцов. Однако в клинической практике такой подход невозможен. Техника отбора проб и устройство, которые мы применяли для получения эндометрального аспирата трансцервикальным путем, позволяют минимизировать риск контаминации, но полностью исключить его невозможно.

В большинстве исследованных образцов эндометрия нами выявлена ДНК лактобацилл, что также согласуется с литературными данными [7]. Ряд авторов рассматривают присутствие лактобацилл в эндометрии как прогностически благоприятный признак для имплантации эмбриона при вспомогательных репродуктивных технологиях и вынашивания беременности [2]. В настоящем исследовании лактобациллы выявляли в большинстве образцов, но в разном количестве и с разным удельным весом в ОБМ.

Облигатно и факультативно анаэробные УПМ были обнаружены в каждом третьем образце эндометрия, как при наличии лактобацилл, так и при их отсутствии. При этом УПМ достоверно реже выявляли у женщин группы нормы по сравнению с пациентками с ХЭ.

На основании доли лактобацилл и УПМ выделили три варианта микробиоты эндометрия, которые с разной частотой определяли у пациенток с ХЭ, ГПЭ и женщин без гистологических признаков патологии эндометрия. Микробиота эндометрия женщин группы нормы в большинстве случаев была представлена одной группой микроорганизмов, как правило, Lactobacillus spp. Выявление этого варианта микробиоты у женщин с ХЭ, вероятно, не требует назначения антибактериальной терапии и согласуется с современными представлениями о преобладании аутоиммунных механизмов в патогенезе ХЭ. Обнаружение УПМ в полости матки женщин с морфологическими признаками эндометрита может быть дополнительным маркером этиологической значимости этих микроорганизмов в развитии воспалительного процесса. Вопрос о взаимосвязи отдельных групп УПМ с развитием ГПЭ требует дальнейшего изучения.

Полученные в ходе настоящего исследования данные подтверждают, что полость матки не является стерильной. 
При этом по ряду параметров микробиота эндометрия схожа с вагинальной микробиотой: в 86,1\% случаев в полости матки были выявлены лактобациллы, а в 63,9\% - они доминировали. В то же время количество микроорганизмов в полости матки в 100-10 000 раз меньше, чем во влагалище. Насколько схожи профили микробиоты верхних и нижних отделов гениталий у женщин и какова роль лактобацилл в полости матки эти вопросы требуют дальнейшего изучения. Также не очевидно, составляют ли микроорганизмы, выявляемые в эндометрии, резидентную или транзиторную микросрлору.

\section{ВЫВОДЫ}

1. Использование ПЦР-РВ позволило выявить бактериальную ДНК в количествах, превышающих показатели для отрицательных контрольных образцов, во всех образцах аспирата эндометрия. 2. В каждом образце аспирата эндометрия выявляли 1-9 групп микроорганизмов. Чаще остальных идентифицировали группу Lactobacillus spp.; данные микроорганизмы обнаружены в 86,1\% проб, в том числе в сочетании с УПМ - в 22,2\%. У 13,9\% пациенток микробиота эндометрия была представлена исключительно УПМ, преимущественно облигатно анаэробными. 3. Интегральная оценка состояния микробного пейзажа эндометрия с учетом доли Lactobacillus spp. и УПМ относительно ОБМ позволила выделить три варианта микробиоты: с преобладанием Lactobacillus spp., с преобладанием УПМ и смешанный. 4. У большинства женщин с гистологически подтвержденным ХЭ в составе микробиоты эндометрия присутствовали УПМ, в то время как при гистологически нормальном эндометрии микробиота была представлена преимущественно Lactobacillus spp. (удельный вес в ОБМ не менее 90\%). 5. В отсутствие единого подхода к диагностике и лечению столь актуальной и распространенной проблемы, как хронический эндометрит, применение современных молекулярно-генетических методов для оценки микробиоты эндометрия и ее роли в возникновении воспалительного процесса выглядит перспективным. Исследование микробиоты полости матки с использованием ПЦР-РВ позволит точно верифицировать диагноз и назначить патогенетически обоснованную терапию, что улучшит прогнозы при последующих беременностях.

\section{Литература}

1. Cicinelli E, Matteo M, Tinelli R, Pinto V, Marinaccio M, Indraccolo U, et al. Chronic endometritis due to common bacteria is prevalent in women with recurrent miscarriage as confirmed by improved pregnancy outcome after antibiotic treatment. Reprod Sci. 2014; (21): 640-7.

2. Moreno I, Codoñer FM, Vilella F, Valbuena D, Martinez-Blanch JF, Jimenez-Almazán $J$, et al. Evidence that the endometrial microbiota has an effect on implantation success or failure. Am J Obstet Gynecol. 2016 Dec; 215 (6): 684-703.

3. Moreno I, Franasiak JM. Endometrial microbiota-new player in town. Fertil Steril. 2017 Jul; 108 (1): 32-39.

4. Perez-Muñoz ME, Arrieta MC, Ramer-Tait AE, Walter J. A critical assessment of the "sterile womb" and "in utero colonization" hypotheses: implications for research on the pioneer infant microbiome. Microbiome. 2017 Apr 28; 5 (1): 48.

5. Baker JM, Chase DM, Herbst-Kralovetz MM. Uterine Microbiota: Residents, Tourists, or Invaders? Front Immunol. 2018 Mar 2; (9): 208.

6. Peric A, Weiss J, Vulliemoz N, Baud D, Stojanov M. Bacteria Colonization of the Female Upper Genital Tract. Int J Mol Sci. 2019 Jul 11; 20 (14) pii: E3405.

7. Цыпурдеева Н. Д., Шипицына Е. В., Савичева А. М., Гзгзян А. М., Коган И. Ю. Состава микробиоты эндометрия и степень выраженности хронического эндометрита у пациенток с неэффективными протоколами экстракорпорального оплодотворения. Есть ли связь? Журнал акушерства и женских болезней. 2018; 67 (2): 5-15.

8. Cicinelli E, Resta L, Nicoletti R, Tartagni M, Marinaccio M, Bulletti C, et al. Detection of chronic endometritis at fluid hysteroscopy. $J$ Minim Invasive Gynecol. 2005 Nov-Dec; 12 (6): 514-8.

9. Espinoza J, Erez O, Romero R, Preconceptional antibiotic treatment to prevent preterm birth in women with a previous preterm delivery. Am J Obstet Gynecol. 2006 Mar; 194 (3): 630-7.

10. Гомболевская Н. А., Марченко Л. А. Современные критерии диагностики хронического эндометрита (обзор литературы). Проблемы репродукции. 2012; 18 (1): 42-46.

11. Kushnir VA, Solouki S, Sarig-Meth T, Vega MG, Albertini DF,

Darmon SK et al. Systemic inflammation and autoimmunity in women with chronic endometritis. Am J Reprod Immunol. 2016; (75): 672-7.

12. Yang R, Du X, Wang Y, Song X, Yang Y, Qiao J. The hysteroscopy and histological diagnosis and treatment value of chronic endometritis in recurrent implantation failure patients. Arch Gynecol Obstet. 2014; (289): 1363-9.

13. Cicinelli E, Matteo M, Tinelli R, Lepera A, Alfonso R, Indraccolo U, et al. Prevalence of chronic endometritis in repeated unexplained implantation failure and the IVF success rate after antibiotic therapy. Hum Reprod. 2015; (30): 323-30.

14. Johnston-MacAnanny EB, Hartnett J, Engmann LL, Nulsen JC, Sanders MM, Benadiva CA. Chronic endometritis is a frequent finding in women with recurrent implantation failure after in vitro fertilization. Fertil Steril. 2010; (93): 437-41.

15. de Goffau MC, Lager S, Salter SJ, Wagner J1, Kronbichler A, Charnock-Jones DS, et al. Recognizing the reagent microbiome. Nat Microbiol. 2018 Aug; 3 (8): 851-3

16. Salter SJ, Cox MJ, Turek EM, Calus ST, Cookson WO, Moffatt MF, et al. Reagent and laboratory contamination can critically impact sequence-based microbiome analyses. BMC Biol. 2014 Nov 12; (12): 87.

17. Mitchell CM, Haick A, Nkwopara E, Garcia R, Rendi M, Agnew K, et al. Colonization of the upper genital tract by vaginal bacterial species in nonpregnant women. Am J Obstet Gynecol. 2015 May; 212 (5): 611.e1-9.

18. Пальцев М. А., Кактурский Л. В., Зайратьянц О. В., редакторы. Патологическая анатомия: национальное руководство. М.: ГЭОТАР-Медиа, 2014; 1264 с.

19. Ворошилина Е. С., Тумбинская Л. В., Донников А. Е., Плотко Е. Э., Хаютин Л. В. Биоценоз влагалища с точки зрения количественной полимеразной цепной реакции: что есть норма? Акушерство и гинекология. 2011; (1): 57-65.

20. Winters AD, Romero R, Gervasi MT, Gomez-Lopez N, Tran MR, Garcia-Flores V, et al. Does the endometrial cavity have a molecular microbial signature? Sci Rep. 2019 Jul 9; 9 (1): 9905. 


\section{References}

1. Cicinelli E, Matteo M, Tinelli R, Pinto V, Marinaccio M, Indraccolo U, et al. Chronic endometritis due to common bacteria is prevalent in women with recurrent miscarriage as confirmed by improved pregnancy outcome after antibiotic treatment. Reprod Sci. 2014; (21): 640-7.

2. Moreno I, Codoñer FM, Vilella F, Valbuena D, Martinez-Blanch JF, Jimenez-Almazán $\mathrm{J}$, et al. Evidence that the endometria microbiota has an effect on implantation success or failure. Am $J$ Obstet Gynecol. 2016 Dec; 215 (6): 684-703.

3. Moreno I, Franasiak JM. Endometrial microbiota-new player in town. Fertil Steril. 2017 Jul; 108 (1): 32-39.

4. Perez-Muñoz ME, Arrieta MC, Ramer-Tait AE, Walter J. A critical assessment of the "sterile womb" and "in utero colonization" hypotheses: implications for research on the pioneer infant microbiome. Microbiome. 2017 Apr 28; 5 (1): 48.

5. Baker JM, Chase DM, Herbst-Kralovetz MM. Uterine Microbiota: Residents, Tourists, or Invaders? Front Immunol. 2018 Mar 2; (9): 208

6. Peric A, Weiss J, Vulliemoz N, Baud D, Stojanov M. Bacterial Colonization of the Female Upper Genital Tract. Int J Mol Sci. 2019 Jul 11; 20 (14) pii: E3405.

7. Tsypurdeeva ND, Shipitsyna EV, Savicheva AM, Gzgzyan AM, Kogan IYu. Composition of endometrial microbiota and chronic endometritis severity in patients with in vitro fertilization failures. Is there any connection? Journal of Obstetrics and Women's Diseases. 2018; 67 (2): 5-15. Russian.

8. Cicinelli E, Resta L, Nicoletti R, Tartagni M, Marinaccio M, Bulletti C, et al. Detection of chronic endometritis at fluid hysteroscopy. $J$ Minim Invasive Gynecol. 2005 Nov-Dec; 12 (6): 514-8.

9. Espinoza J, Erez O, Romero R, Preconceptional antibiotic treatment to prevent preterm birth in women with a previous preterm delivery. Am J Obstet Gynecol. 2006 Mar; 194 (3): 630-7.

10. Gombolevskaia NA, Marchenko LA. Modern diagnostic criteria of chronic endometritis (a review). Russian Journal of Human Reproduction. 2012; 18 (1): 42-6. Russian.

11. Kushnir VA, Solouki S, Sarig-Meth T, Vega MG, Albertini DF,
Darmon SK et al. Systemic inflammation and autoimmunity in women with chronic endometritis. Am J Reprod Immunol. 2016; (75): $672-7$

12. Yang R, Du X, Wang Y, Song X, Yang Y, Qiao J. The hysteroscopy and histological diagnosis and treatment value of chronic endometritis in recurrent implantation failure patients. Arch Gynecol Obstet. 2014; (289): 1363-9.

13. Cicinelli E, Matteo M, Tinelli R, Lepera A, Alfonso R, Indraccolo U, et al. Prevalence of chronic endometritis in repeated unexplained implantation failure and the IVF success rate after antibiotic therapy. Hum Reprod. 2015; (30): 323-30.

14. Johnston-MacAnanny EB, Hartnett J, Engmann LL, Nulsen JC, Sanders MM, Benadiva CA. Chronic endometritis is a frequent finding in women with recurrent implantation failure after in vitro fertilization. Fertil Steril. 2010; (93): 437-41.

15. de Goffau MC, Lager S, Salter SJ, Wagner J1, Kronbichler A, Charnock-Jones DS, et al. Recognizing the reagent microbiome. Nat Microbiol. 2018 Aug; 3 (8): 851-3.

16. Salter SJ, Cox MJ, Turek EM, Calus ST, Cookson WO, Moffatt MF, et al. Reagent and laboratory contamination can critically impact sequence-based microbiome analyses. BMC Biol. 2014 Nov 12; (12): 87.

17. Mitchell CM, Haick A, Nkwopara E, Garcia R, Rendi M, Agnew K, et al. Colonization of the upper genital tract by vaginal bacterial species in nonpregnant women. Am J Obstet Gynecol. 2015 May; 212 (5): 611.e1-9.

18. Palcev MA, Kakturskij LV, Zajrat'janc OV, editors. Pathological anatomy: national guide. M.: GJeOTAR-Media, 2014; 1264 p.

19. Voroshilina ES, Tumbinskaya LV, Donnikov AE, Plotko EA, Khayutin LV. Vaginal biocenosis in the context of view of quantitative polymerase chain reaction: what is its norm? Obstetrics and Gynecology. 2011; (1): 57-65. Russian.

20. Winters AD, Romero R, Gervasi MT, Gomez-Lopez N, Tran MR, Garcia-Flores V, et al. Does the endometrial cavity have a molecular microbial signature? Sci Rep. 2019 Jul 9; 9 (1): 9905. 